South Dakota State University

Open PRAIRIE: Open Public Research Access Institutional Repository and Information Exchange

Health and Nutritional Sciences Faculty

Publications

Health and Nutritional Sciences

9-2009

The Medicine Wheel Nutrition Intervention: a Diabetes Education Study with the Cheyenne River Sioux Tribe

Kendra K. Kattelmann

Kibbe Conti

Cuirong Ren

Follow this and additional works at: https://openprairie.sdstate.edu/hns_pubs 


\section{The Medicine Wheel Nutrition Intervention: A Diabetes Education Study with the Cheyenne River Sioux Tribe}

Kendra K. Kattelmann, PhD, RD [Professor and Director Didactic Program in Dietetics], Box 2275A, Nutrition, Food Science \& Hospitality Department, South Dakota State University, Brookings, South Dakota 57007, Fax: 605-688-5603, Telephone: 605-688-4045, Kendra.kattelmann@sdstate.edu

Kibbe Conti, MS, RD [at the time of the study was a graduate student in the NFSH department], and 6134 Wildwood Drive, Rapid City, South Dakota 57702, Telephone: 605-341-1477, Kibbe1@msn.com

Cuirong Ren, PhD [Professor of statistics]

Box 2207A, Plant Science Department, South Dakota State University, Brookings, SD 57007, Telephone: (605) 688-4748, Cuirong.Ren@sdstate.edu

\section{Abstract}

Objective-The Northern Plains Indians of the Cheyenne River Sioux Tribe (CRST) have experienced significant lifestyle and dietary changes over the past seven generations that have resulted in increased rates of diabetes and obesity. The objective of this study was to determine if Northern Plains Indians with type 2 diabetes mellitus who are randomized to receive culturally adapted educational lessons based on the Medicine Wheel Model for Nutrition in addition to their usual dietary education will have better control of their type 2 diabetes than a non-intervention, usual care group who received only the usual dietary education from their personal providers.

Design-A 6-month, randomized, controlled trial was conducted January 2005-December 2005, with participants randomized to Education (ED) intervention or Usual Care (UC) control group. ED received six nutrition lessons based on the Medicine Wheel Model for Nutrition. UC received the usual dietary education from their personal providers.

Participants-114 Northern Plains Indians from Cheyenne River Sioux Tribe aged 18 to 65, with type 2 diabetes.

Methods-Weight, body mass index (BMI), hemoglobin A1C, fasting serum glucose and lipid parameters, circulating insulin, and blood pressure were measured at the beginning and completion. Diet histories, physical activity and dietary satiety surveys were measured at baseline and monthly through completion. Differences were determined using Students t-tests, chi-square, and analysis of variance.

Results-The ED group had a significant weight loss $(1.4 \pm 0.4 \mathrm{~kg}$, mean \pm standard error $\{\mathrm{SE}\}$, $\mathrm{P} \leq .05)$ and decrease in BMI $(1.0 \pm 0.1$ means $\pm \mathrm{SE}, \mathrm{P} \leq .05)$ from baseline to completion. The UC group had no change in weight $(0.5 \pm 0.5 \mathrm{~kg}$, mean $\pm \mathrm{SE})$ or BMI $(0.5 \pm 0.2$, mean $\pm \mathrm{SE})$. There were

(C) 2009 The American Dietetic Association. Published by Elsevier Inc. All rights reserved.

Correspondence to: Kendra K. Kattelmann.

Publisher's Disclaimer: This is a PDF file of an unedited manuscript that has been accepted for publication. As a service to our customers we are providing this early version of the manuscript. The manuscript will undergo copyediting, typesetting, and review of the resulting proof before it is published in its final citable form. Please note that during the production process errors may be discovered which could affect the content, and all legal disclaimers that apply to the journal pertain. 
no between group differences due to intervention in calorie, carbohydrate, protein, and fat intake and physical activity.

Conclusions-The culturally based nutrition intervention promoted small but positive changes in weight. Greater frequency and longer duration of educational support may be needed to influence blood glucose and lipid parameters.

\section{Keywords}

diabete

\section{Introduction}

The Cheyenne River Sioux people have witnessed major dietary transitions over the past seven generations. The beginning of this transition occurred simultaneously with the rapid decline in the buffalo and the loss of much of their traditional hunting grounds. For Northern Plains Indians diabetes was non-existent when they were consuming a diverse variety of wild plants and animals that were rich in protein, moderate in carbohydrate, low in fat [1] and rich in antioxidants. The diet consisted mostly of large game, and wild plants used for food, medicine and teas, including the wild turnip, wild potato, onion, mushrooms, other roots, nuts and seeds and a variety of berries [2]. Corn, beans and squash were available through trade with neighboring tribes. The wild foods were slowly digested and absorbed allowing blood sugar levels to keep in balance with insulin production [3]. Plains Indians may have co-evolved with these foods over millennia. In the early years of the reservation until the 1950's the Cheyenne River Sioux were involved in food production; gardening, hunting and gathering, which, combined with monthly government issued rations, provided most all the dietary components. In 1959, the Tribal Agency was forced to move, as a result of the Oahe Dam project; the Missouri river was dammed and flood waters inundated the Agency community [4]. Most of the best agricultural lands and berry picking areas along the river were flooded. Traditional foods were gradually replaced with new western foods available in government food packages and food markets as more Native Americans participated in the modern economy, a change that became most prominent following World War II [1]. Today, a few traditional foods remain: traditional soups and stews some made with dried corn and dried buffalo (papa) and prairie turnip (tinpsila), tripe soup (taniga), stewed berries (wojapi), wild mint teas, wasna or pemmican, and kabubu bread - a skillet bread. As one Lakota woman explains "Most Indians today eat a poor white man's diet. It is very difficult to get food, especially fresh food here on the reservation. True Indian food is a delicacy today." [5]

Coinciding with the diet change, health concerns have changed drastically during the past 50 years. Formerly infectious disease and malnutrition among children were significant problems on the reservation, [6] while today chronic disease related to behavior and lifestyle factors are now the leading cause of morbidity and mortality in adults [7]. American Indian/Alaska Natives experience diabetes prevalence rates three times higher than the overall United States population. [8]. Tribes in the Dakotas, Iowa and Nebraska (Aberdeen Area of Indian Health Service) report an age adjusted diabetes prevalence rate of 13.72 per 1000 in American Indians less than 35 years of age [9]. This is four times the rate of diabetes prevalence for similar age groups in these states. [10].

Even though, glycolic control for Native Americans 55 years and under has improved significantly over the past ten years, the mean $\mathrm{HgA1C}$ is 7.9 which are higher than the recommended $\mathrm{HgA} 1 \mathrm{C}$ level of 7.0 or less [11]. Complications of diabetes can be prevented by good glycolic control [12]. Medical nutrition therapy is an important component of diabetes self-management and thus glycolic control. At present, there are no dietary guidelines specific 
for the Northern Plains Indians. Current medical nutrition therapy practices base the diabetic therapeutic guidelines on the United States Department of Agriculture food guidelines, My Pyramid, which encourages a grain-based diet [13]. Anecdotally, Northern Plains Indians have reported better control of their type 2 diabetes when following a diet that is higher in protein. Genetic differences may contribute to less than optimal adaptation to higher carbohydrate loads among Native Americans compared to Northern European descendents [14]. A diet patterned after the historical hunter-gatherer type diet, or even the early reservation diet (with the higher proportion of energy being supplied from protein), may provide better blood glucose control and lower the circulating insulin levels in Northern Plains Indians with type 2 diabetes.

It has been suggested that more culturally and tribally specific intervention approaches might lead to greater behavioral change than standardized interventions [15]. The objective of this study was to determine if Northern Plains Indians with type 2 diabetes mellitus who are randomized to receive culturally adapted educational lessons based on the Medicine Wheel Model for Nutrition in addition to their usual dietary education will have better control of their type 2 diabetes than a non-intervention, usual care group who received only the usual dietary education from their personal providers. It was hypothesized that culturally adapted lessons will enhance dietary adherence and control of blood glucose in those with type 2 diabetes.

\section{Methods}

\section{Overall Research Design}

In 2005, 114 Northern Plains Indians from the Cheyenne River Sioux Reservation, aged 18 to 65 , with type 2 diabetes were recruited through local newspaper advertisements, local public radio announcements, and posters in the Tribal Health Clinic. Eligible participants were stratified by gender and body mass index (BMI) and were randomized using a computer generated random number chart into a six month dietary education intervention (ED) or usual care, control group (UC). The ED group received six nutrition education lessons using the Medicine Wheel Nutrition Model [16] delivered once per month in addition to their usual dietary education provided by their personal health care providers. The Medicine Wheel Nutrition Model uses the Medicine Wheel diagram to promote a diet patterned according to the traditional consumption of macronutrients (Figure 1). The UC group was treated as nonintervention control and received the standardized dietary education provided by their personal health care providers at the local Indian Health Services Hospital. At the time of the study the hospital did not have a registered dietitian on staff. Indian Health Services outlines the standards of care for treatment of those with diabetes. These guidelines state that the medical nutrition therapy for diabetes is based on the American Diabetes Association Standards of Medical Care for Diabetes [17]. The UC participants were assessed with the same measurements at the same time periods as the ED participants. The study was conducted from January 2005 through December 2005.

\section{Setting and Participants}

The recruitment and study occurred on the Cheyenne River Sioux Reservation. Missouri Breaks Industries, a local Native American owned company, assisted with recruitment and transportation of participants to study visits. The reservation is located in western South Dakota on one of the largest intact grasslands left in the United States. The reservation is home to 8,500 Cheyenne River Sioux Tribal members who are spread across the 3 million acre land base, with an average population density of 1-3 persons per square mile and divided into 13 district communities. Each district has its own political representation within the tribe. The median age of people living on the Cheyenne River Reservation is 25.8 years [18]. 
Native American's who had a previous diagnosis by their personal physicians with no compromised renal function were eligible to participate. Participants self reported their race and tribal affiliation. For eligibility in the study, participants agreed not to consume over-thecounter supplements and alcohol during the study period. Participants were excluded if they were entered alcohol treatment. Potential participants were excluded if self-reported compromised renal function or presence of microalbuminuria (urinary albumin $>30 \mathrm{mg} / 24 \mathrm{hr}$ ) determined through urinalysis at recruitment visit [19]. Institutional Review Boards of the Aberdeen Area Indian Health Services, South Dakota State University, and the Health Committee of the Cheyenne River Sioux Tribal Council approved the study and all participants provided written consent prior to enrolling. Participants received a small cash incentive (\$10.00/survey) for completion of surveys.

\section{Program Interventions}

The Medicine Wheel Nutrition Model education lessons delivered to the Education group were used to encourage participants to consume a diet patterned after the traditional consumption of macronutrients for Northern Plains Indians; protein (25\% of calories), moderate in carbohydrate ( $45 \%-50 \%$ of calories), low in fat (25-30\% of calories). Data collection took place at a field site, on the Cheyenne River Indian Reservation run by Missouri Breaks Industries Inc., during an initial 90 minute appointment and prior to each monthly lesson.

The Education group received monthly dietary counseling on the Medicine Wheel Model for Native Nutrition in a small group (5-9 participants). A registered dietitian and tribal member, trained in the curriculum, led the two-hour classes covering the monthly topics. Each participant's total energy requirement was estimated using the Mifflin-St. Jeor equation [20]. Participants were provided an individualized meal plan built upon the four meal components of the Medicine Wheel Nutrition Model [16] that met the individual's energy requirements. This model emphasized the four healthful components of a traditional hunter-gatherer diet which corresponds with the symbolism of the Medicine Wheel (Figure 1). The model limits highly refined starchy foods and prevents carbohydrate loading similar to the pre-reservation dietary consumption patterns [21].

The class sessions were on the following topics during the trial: Lesson 1--The Medicine Wheel Model for Native Nutrition/Individualized meal plans; Lesson 2--Self Monitoring of Eating; Lesson 3--Self Monitoring of Physical Activity; Lesson 4--Changing the Environment to Promote Food Choices in Keeping with Tradition; Lesson 5--Eating at Home: Food Preparation Techniques; Lesson 6--Problem Solving. After each lesson participants were given the opportunity to attend a group support session called a Talking Circle. A Talking Circle is a method of intra-group communication in many Indian Communities [22,23,24]. At completion of the trial the UC participants were offered the same classes as those provided the ED participants. Project investigators were not blinded to intervention.

\section{Outcome Measures}

Weight, BMI, hemoglobin A1C, fasting serum glucose concentrations, total cholesterol, low density lipoprotein cholesterol, high density lipoprotein cholesterol, triglycerides, circulating insulin concentration, and blood pressure were measured at the beginning and end of trial. All study personnel were trained and measurements were taken in duplicate and averaged. Participants were instructed to wear light clothing and remove shoes for weight and height measurements. Weights were measured using a digital scale (Tanita BWB 800, Tanita Corporation, Arlington Heights, Illinois) and heights were measured by a wall mounted stadiometer (Seca 222, Seca North America East, Hanover, MD). Blood samples were collected after a 12 hour fast and analyzed at a Clinical Laboratory Improvement Amendments-certified laboratory. Participants completed 24-hour diet histories, Cross-Cultural Activity Participation 
Study (CAPS) physical activity survey [25,26], and a satiety survey with a rating scale designed to measure subjective satiety of the diet [27] at baseline and then monthly through completion. Diet histories were collected using 24-hour recall by registered dietitian and trained study personnel. All personnel collecting dietary histories were trained by a registered dietitian and followed a written script. CAPS physical activity survey defined light activity as easy or no effort at all; moderate activity as an activity that leads to some increase in breathing or heart rate and vigorous activity to include activities with a large increase in breathing or heart rate. Participants were also queried for medication changes and incidence of infection and illnesses at each visit. A short health history questionnaire which included questions about past medical history, current medications and supplement use was completed upon enrollment.

\section{Dietary Analysis}

Adherence to the dietary and exercise protocol was determined from diet histories and activity diaries collected monthly. Diet histories were reviewed for completeness by one registered dietitian prior to analysis. Participants were contacted by telephone to clarify discrepancies. The dietary data was analyzed for energy, carbohydrate, protein and fat using Food Processor (version 8.6, 2005, ESHA Research, Salem, Oregon).

\section{Data Analysis}

Targeted recruitment of 114 participants (57/group) was based on results reported by Knowler [12] and Gilliland [28]. Knowler reported a between group difference of $0.2 \%$ in HgAlc after a 6 month lifestyle intervention. Gilliliand reported a difference of $0.8 \%$ with a standard deviation of $0.3 \%$ in $\mathrm{HgAlc}$ between intervention and control after a one year lifestyle intervention trial in a Native American population. To be conservative the smaller difference between means reported by Knowles $(0.2 \%)$ and the standard deviation provided by Gilliland $(0.3 \%)$ were used to calculate a sample size of 57 per group (two-sided alpha $=0.05,80 \%$ power, and $70 \%$ completion rate).

Data was checked for normality. Statistical significance of non-normal data was determined on transformed data and geometric means, $95 \%$ confidence intervals are reported for transformed data. Means and standard errors are reported on normal data. Repeated measures of analysis of variance were used to detect differences across time and between groups. Overall changes for within and between group were determined using Students t-tests, chi-square, and analysis of variance. Analyses included PROC TTEST and PROC MIXED of SAS ${ }^{\circledR}$ (SAS, Version 9, 2004, SAS Institute Inc., Cary, North Carolina).

\section{Results}

Of the 114 participants who gave written consent to participate, 104 completed the study. Data was missing on 10 participants ( 8 failed to return for the intervention, one was excluded for hospitalization for alcoholism, and one withdrew due to major intestinal surgery). Seventy-six percent of the participants were women. Seventy-two percent of participants were obese (BMI $>30$ ) and $23 \%$ were overweight (BMI >25). There were no differences in age, height, or gender between ED and UC (Table 1).

There were no differences between ED a nd UC for any of the baseline measures. When evaluating the within group changes from baseline to completion, the ED group had a significant mean weight loss and decrease in BMI from baseline to completion, whereas the UC group had no change in weight or BMI from baseline to completion. The UC group reported significant decreases from baseline to completion in total cholesterol and HDL cholesterol. There were no other significant within group changes from baseline to completion. 
When comparing the between group baseline to completion changes, there was a significant difference for the change in triglyceride This was due to the ED group experiencing a slight increase in triglycerides with no change in the UC group from baseline to completion. There were no differences in between group changes for any of the other parameters measured (Table $1)$.

To account for changes in glucose control that may have occurred due to medications or illness participants were queried each visit for medication changes and any significant health events (defined as illnesses that you had to see your doctor) that may have occurred since the previous visit. There were no significant differences between groups at any of the visits for self-reported medication changes and significant health events.

There was no difference due to time or intervention in caloric, carbohydrate, or fat intake (Table 2). Protein as a percent of calories did trend upward over time in the intervention group, nearing significance $(\mathrm{P}=0.068)$ only due to time and not the intervention. Although not significant, the mean intake of fat trended downward among intervention participants and met the American Heart Association's guideline to limit fat to less than $35 \%$ of calories by study completion.

There were no differences due to time or intervention for the moderate and vigorous activity levels. In the light activity category there was an effect due to time $(\mathrm{F}$ value $=5.51, \mathrm{P} \leq .0001)$ but not due to intervention. Since there was no group difference, the groups were combined and means for time spent in light activity are reported (Table 2). Both groups reported a decrease from baseline and month 2 to months $4,5, \& 6$ in number of light activity minutes.

There was no significant difference between ED and UC groups in the self-reported dietary adherence and satiety of diet (feeling of fullness) at any of the visits. Month 2 to completion "some of the time" and "most of the time" accounted for greater than $80 \%$ of the responses marked for dietary adherence in both of the groups. Month 2 to completion "most of the time" and "all the time" accounted for $56 \%$ to $70 \%$ of responses in both groups to feeling full.

\section{Discussion}

Schultz el. al reported that Pima Indians living in Mexico (traditional environments) have a much lower prevalence of type 2 diabetes and obesity than those living in the Westernized environment of the United States [29,30]. Anecdotally, Northern Plains Indians have reported better control of their type 2 diabetes when following a diet that is higher in protein. A diet patterned after the historical hunter-gatherer type diet, or even the early reservation diet (with the higher proportion of energy being supplied from protein), may provide better blood glucose control and lower the circulating insulin levels in Northern Plains Indians with type 2 diabetes [14]. Tribal leaders are interested in preserving the history of their food patterns and embrace the development of educational tools depicting their historical consumption patterns [16]. This trial is one of the first studies reported that attempts to measure the influence of the traditional Northern Plains Indians diet on control of type 2 diabetes. The goal of the Medicine Wheel Model for Nutrition intervention was to provide dietary instruction that was sufficient to empower the participants to choose diets that pattern the traditional diet ( $25 \%$ of calories from protein, 45-50\% from carbohydrate, and 25-30\% from fat). However, the education intervention was not able to empower the participants to make the dietary changes. When one compares the dietary intakes of both the ED and UC group with the Third National Health and Nutrition Examination Survey (NHANEA III) data, macronutrient intakes were similar to the overall US population as surveyed in NHANES [31] and to those reported in The Strong Heart Dietary Study - Phase 2 [32]. The intervention promoted protein foods to comprise 20-25\% of calories. Although the participants did not report reaching this goal, there was an upward trend in protein intake in the education group occurred over time. This trend may reflect 
participants choosing leaner protein sources such as buffalo, leaner cuts of beef and pork, and other lean meats as emphasized in the lessons and in food demonstrations. Carbohydrate intake was consistent in both groups; fat intake trended downward in the intervention group while protein intake trended from $14 \%$ to $18 \%$ for the intervention group during the trial.

There are several potential reasons to explain the lack of dietary compliance within this study. The diet and lifestyle intervention tailored specifically to Northern Plains Indians may not have allowed sufficient time both in duration and frequency for comprehension and adoption of dietary behavior changes in this specific population. The monthly frequency of the intervention, even with good participation, ( $92 \%$ attendance rate) potentially lacked the intensity required to support improvements in blood sugar control or in the lipid profile of participants. The Diabetes Prevention Program (DPP) reported successful control in blood glucose parameters due to lifestyle changes in those participants without diabetes but with elevated glucose concentrations. The DPP intervention group had frequent contact which consisted of weekly contacts during an initial 16 week period, then no less than monthly thereafter [33]. It also used a combination of individual and group intervention. The current study's focus on individual behavior change via education, though necessary, may not have been in sufficient dose to enable patient in their environments to make the necessary diet and lifestyle changes. Environmental factors such as social norms, food access and food supply, income and others have a significant role in food selection. The family structure for many participants is the extended family unit, with multiple generations living together. Food decisions reflect the needs of the family unit and may not cater to an individual's medical nutrition needs. Personal health concerns may be secondary to those of the greater extended families. Baranowski and colleagues reported that environmental influences may be more important and influential than psychosocial factors [34].

Participants in this trial had no meaningful change in physical activity. Only six percent of study participants met the Surgeon General's recommendation for getting 30 minutes of exercise on most days of the week or 150 total minutes per week. This study population is more sedentary by comparison with national and state data on adult activity patterns, reporting that approximately $20 \%$ of South Dakota adults meet the Surgeon General's recommendation [35]. Encouraging participants to increase physical activity on a regular basis may require intensive behavioral support similar to that required to change dietary behavior. Additional community support may be necessary to enhance physical activity levels. Native Americans living on reservations report lack of child care, lack of time, and safety concerns as barriers to engaging in regular physical activity [36].

Although there were not significant changes in dietary intake and physical activity, the high level of participation in this trial was one of the successes of the study. Ninety percent of those enrolling completed the trial and greater than $92 \%$ of the education participants attended 4 out of the 6 education lessons. The study was not designed to determine why the participation level was higher than expected. The high level of participation may have been due to several factors. The Medicine Wheel Model for Native Nutrition tool was designed by a tribal member with input from the tribal leaders and members. Additionally, the tribal leaders were consulted prior to designing the intervention, transportation was provided to the study visits, and the intervention was delivered by a tribal member. Another potential reason for high participation may have been due to the timing of the study. Due to input from the tribal leaders, the study was planned to occur after the summer tribal celebrations and before the Christmas holiday.

\section{Conclusions}

This study was not able to substantiate or refute that the traditionally dietary patterns of the Northern Plains Indians produce better control of type 2 diabetes due to reported lack of dietary 
compliance. Anecdotally, participants have reported better control of glucose patterns following diets patterned after the hunter gather, this study was not able to produce compliance with the dietary pattern to support or refute. In addition to increased intensity and longer duration of the delivery method of the dietary intervention, future research involving dietary change may need to include an emphasis on environmental issues such as food access, poverty, public policy, peer and family level influences in designing an intervention method.

One success of the study was high level of participation. Ninety-two percent of the participants who enrolled attended four of the six monthly sessions. The study was not designed to measure the determinants for level of participation. However, input from the tribal leaders and members prior to and during the planning for the study may have provided the positive influence needed for participation and should be considered for future studies of this population.

\section{Supplementary Material}

Refer to Web version on PubMed Central for supplementary material.

\section{References}

1. Jackson, YB. Diet, culture, and diabetes. In: Joe, JR.; Young, RS., editors. Diabetes as a Disease of Civilization: The Impact of Culture Change on Indigenous Peoples. Berlin, Germany: Walter de Gruyter and Co; 1993. p. 382-406.

2. Nurge, E. Dakota Diet: Traditional and Contemporary. The Modern Sioux: Social Systems and Reservation Culture. Lincoln, NE: University of Nebraska Press; 1970. p. 35-91.

3. Brand-Miller JC, Snow BJ, Nabhan GP, Truswell AS. Plasma glucose and insulin responses to traditional Pima Indian meals. Am J of Clin Nutr 1990;51:416-420. [PubMed: 2178389]

4. Coon, M. Oahe Dam; Master of the Missouri. Irvington, NY: Harvey House Inc; 1969.

5. Cohen E. After Wounded Knee: The feeding of the American Indian. Food Management 1970 April;: 28-80.

6. Department of Health. A Report of a Regional Task Force. US Public Health Service; 1973. The Health of The American Indian. p. 1-31.

7. Indian Health Service. Trends in Indian Health: 1998-1999. Rockville, MD: Office of Public Health, US Dept. of Human Health and Service; 2001. p. 1-272.

8. Indian Health Service. Indian Health Service 2006 National Summary. Government Performance and Results Act, Indian Health Service. US Dept. of Human Health and Service; 2007 [Accessed June 28, 2007]. p. 1-39.Available at:

http://www.ihs.gov/NonMedicalPrograms/PlanningEvaluation/documents/2006\%20National\% 20Summary(Public013007).pdf

9. Acton K, Burrows NR, Moore K, Querec L, Geiss LS, Engelgau M. Trends in diabetes prevalence among American Indian and Alaska native children, adolescents, and young adults. Am. M. Public Health 2002;92:1485-1490.

10. Center for Disease Control and Prevention. Diabetes Data \& Trends. [Accessed December 30, 2008]. Available at http://apps.nccd.cdc.gov/ddtstrs/default.aspx

11. Wilson C, Gilliland S, Cullen T, Moore K, Roubideaux Y, Valdez L, Vanderwagen W, Acton K. Diabetes outcomes in the Indian health system during the era of special diabetes program for Indians and the government performance and results act. Am. J. Public Health 2005;95:1518-1522. [PubMed: 16051933]

12. Diabetes Prevention Program Research Group. Reduction in the incidence of type 2 diabetes with lifestyle intervention or metformin. New Engl J Med 2002;346:393-403. [PubMed: 11832527]

13. Food and Nutrition Information Center, US Department of Agriculture. My Pyramid Plan. [Accessed April 1, 2007]. Available at: http://www.mypyramid.gov/mypyramid/index.aspx

14. Szathmary E. The impact of low carbohydrate consumption on glucose tolerance, insulin concentration and insulin response to glucose challenge in Dogrib Indians. Med Anthropol 1989;11:329-350. [PubMed: 2671575] 
15. Gittelsohn J, Davis SM, Steckler A, Ethelbah B, Clay T, Metcalfe L, Rock BH. Pathways: lessons learned and future directions for school-based interventions among American Indians. Prev Med 2003;37:S107-S112. [PubMed: 14636815]

18. US Bureau of the Census. American Indian and Alaska Native Summary File: Median Age by Sex. Washington, DC: US Bureau of Census; 2000.

16. Conti KM. Diabetes prevention in Indian country: developing nutrition models to tell the story of food-system change. J Transcult Nurs 2006;17:234-245. [PubMed: 16757662]

17. Indian Health Service Standards of Care for Adults with Type 2 Diabetes. 2006 Sep [Accessed December 29, 2008]. Available at http://www.ihs.gov/MedicalPrograms/Diabetes/HomeDocs/Tools/ClinicalG uidelines/ Standards_Care_0806.pdf

19. Morgensen CE, Keane WF, Bennett PH, Striker GE, Jerums G, Parving HH, Passa P, Steffes MW, Viberti GC. Prevention of diabetic renal disease with special reference to microalbuminemia. Lancet 1995;346:1080-1085. [PubMed: 7564792]

20. Mifflin MD, St Joer ST, Hill LA, Scott BJ, Daugherty SA, Koh YO. A new predictive equation for resting energy expenditure in healthy individuals. Am J Clin Nutr 1990;51:241-247. [PubMed: 2305711]

21. Meyer, RW. The villiage Indians of the upper Missouri: The Mandans, Hidatsas and Arikaras. Lincoln, NE: University of Nebraska Press; 1977.

22. Hodge FS, Stubbs H. Talking circles: increasing cancer knowledge among American Indian women. Cancer Research and Therapy 1999;8:103-111.

23. Hodge FS, Pasqua A, Marquez CA, Geishirt-Cantrell B. Utilizing traditional storytelling to promote wellness in American Indian communities. J Transcult Nurs 2002;13:6-11. [PubMed: 11776018]

24. Running Wolf P, Rickard JA. Talking circles: a Native American approach to experiential learning. J of Multicultural Counseling and Development 2003;31:43.

25. Ainsworth BE, Richardson MT, Jacobs DR Jr. Leon AS, Sternfeld B. Accuracy of recall of occupational physical activity by questionnaire. J Clin Epoidemiol 1999;52:219-227.

26. Ainsworth BE, Irwin ML, Addy CL, Whitt MC, Stolarczyk LM. Moderate physical activity patterns of minority women: the cross-cultural activity participation study. J Womens Health Gend Based Med 1999;8:805-813. [PubMed: 10495261]

27. Holt SHA, Brand Miller JC, Petocz P, Farmakalidis E. A satiety index of common foods. Eur J Clin Nutr 1995;49:675-690. [PubMed: 7498104]

28. Gilliland S, Azen S, Perez G, Carter J. Strong in body and spirit: Lifestyle intervention for Native American adults with diabetes in New Mexico. Diabetes Care 2002;25:78-83. [PubMed: 11772905]

29. Williams DE, Knowler WC, Smith CJ, Hanson RL, Roumain JR, Saremi AS, Kriska AM, Bennett $\mathrm{PH}$, Nelson RG. The effect of Indian and Anglo Dietary preference on the incidence of diabetes in Pima Indians. Diabetes Care 2001;24:811-816. [PubMed: 11347735]

30. Schulz LO, Bennett PH, Ravussin E, Kidd JR, Kidd KK, Esparza J, Valencia ME. Effects of traditional and western environments on prevalence of type 2 diabetes in Pima Indians in Mexico and the U.S. Diabetes Care 2006;29:1866-1871. [PubMed: 16873794]

31. Wright, JD.; Wang, CY.; Kennedy-Stephenson, J.; Ervin, RB. Advance Data: From Vital and Health Statistics. Hyattsville, MD: Centers for Disease Control and Prevention, U.S. Dept. of Health and Human Services; 2003 Apr 17. Dietary Intake of Ten Key Nutrients for Public Health, United States: 1999-2000. p. 1-4.Available at: http://www.cdc.gov/nchs/data/ad/ad334.pdf

32. Stang J, Zephier E, Story M, Himes J, Yeh J, Welty T, Howard B. Dietary intakes of nutrients thought to modify cardiovascular risk from three groups of American Indians; the strong heart dietary study, phase II. J Am Diet Assoc 2005;105:1895-1903. [PubMed: 16321595]

33. Diabetes Prevention Program Research Group. The diabetes prevention program: design methods for a clinical trial in the prevention of type 2 diabetes. Diabetes Care 1999;22:623-634. [PubMed: 10189543]

34. Baranowski T, Cullen KW, Baranowski J. Psychosocial correlates of dietary intake: advancing dietary intervention. Annu Rev Nutr 1999;19:17-40. [PubMed: 10448515] 
35. Center of Disease Control and Prevention. Behavioral Risk Factor Surveillance System. Department of Health and Human Services, National Center for Chronic Disease Prevention and Health Promotion; 2007 [Accessed December 30, 2008]. http://www.cdc.gov/brfss/index.htm

36. Harnack L, Story M, Holy Rock B. Diet and physical activity patterns of Lakota Indian adults. J Am Diet Assoc 1999;99:829-835. [PubMed: 10405681] 


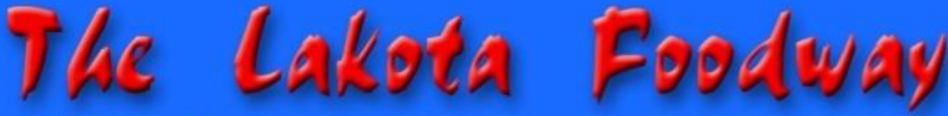

1860 s \& Earlier

In Traditional times, our people enjoyed superior health as everything they ate came from Mother Earth.

The West Wind Brings the rain clouds to nourish all living things.

The North Wind Gives us the Buffalo and other grass eating animals to hunt.

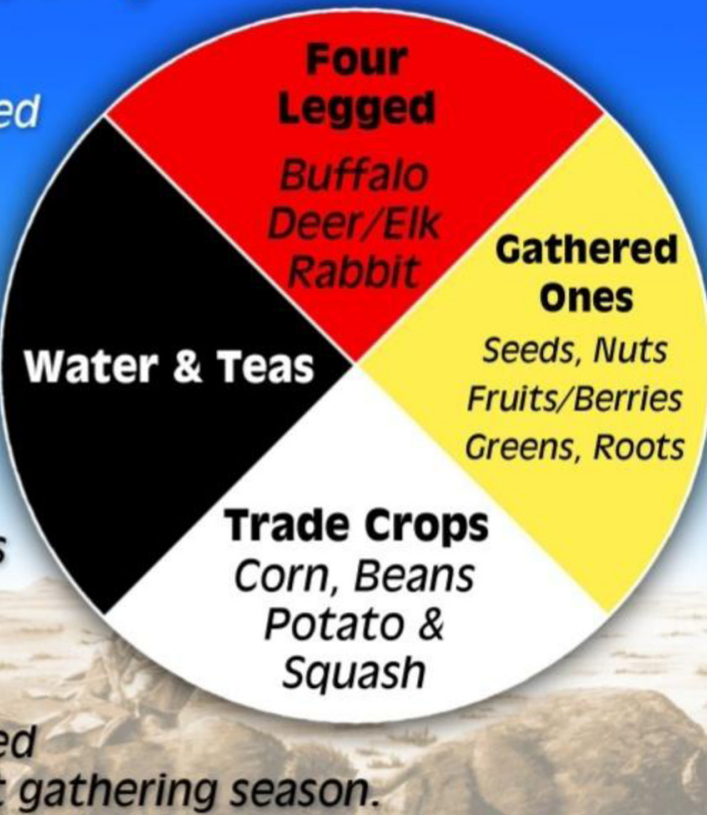

The East Wind Corn, Beans Potato \& Brings Springtime, a time of renewed plant growth \& beginning of the plant gathering season.

\section{The South Wind}

Brings the warm summer wind and the growing season for our cultivated plants used in trade.

Figure 1.

The Medicine Wheel, representing the four dietary components of the traditional Northern Plains Indian hunter/gatherer food pattern. 

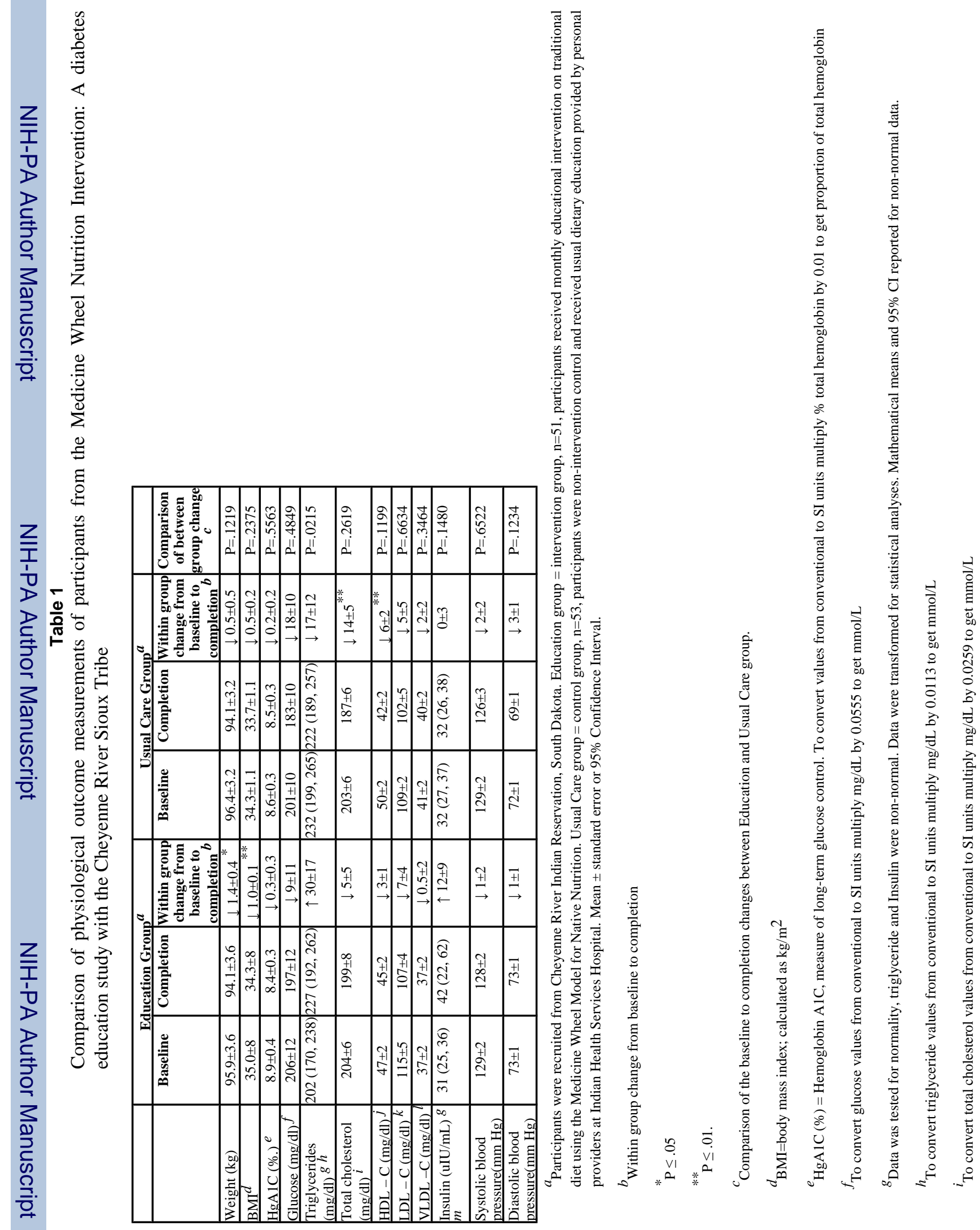

$J$ Am Diet Assoc. Author manuscript; available in PMC 2010 September 1. 


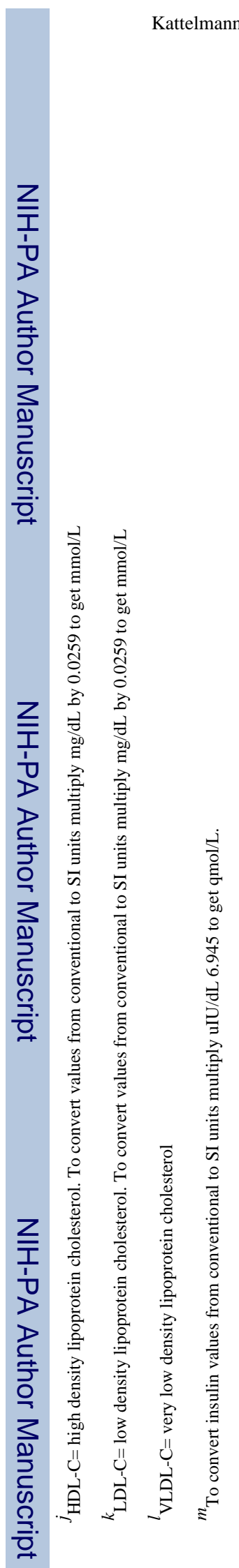

Page 13

$J$ Am Diet Assoc. Author manuscript; available in PMC 2010 September 1. 


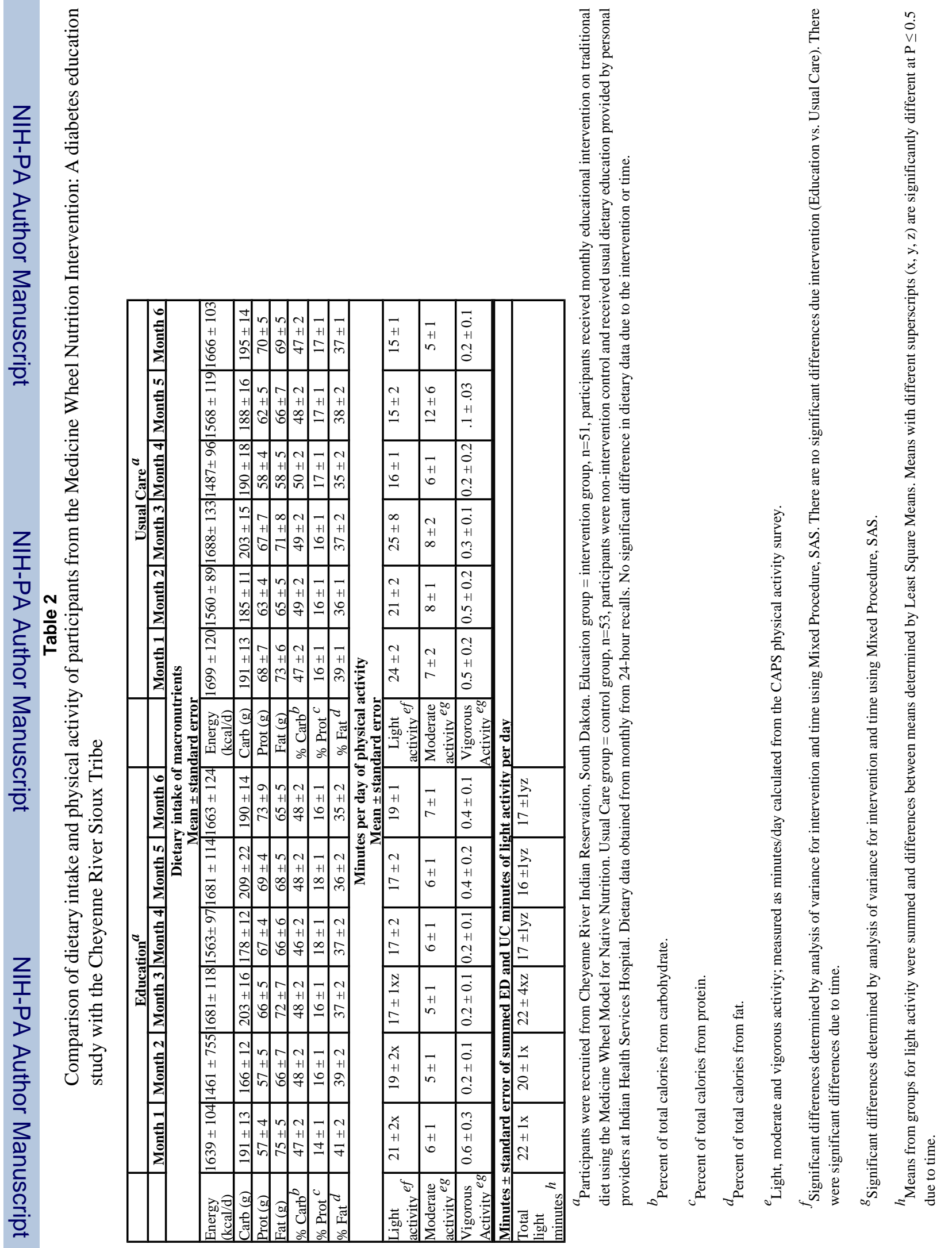

